\title{
Hyperlipidemia due to hepatic triacylglycerol lipase deficiency
}

INSERM

\section{Source}

INSERM. (1999). Orphanet: an online rare disease and orphan drug data base. Hyperlipidemia due to hepatic triacylglycerol lipase deficiency. ORPHA:140905

Hyperlipidemia due to hepatic triacylglycerol lipase deficiency is a rare, genetic hyperalphalipoproteinemia disorder characterized by elevated plasma cholesterol and triglyceride $(T \mathrm{G})$ levels with a marked T G enrichment of low- and high-density lipoproteins (HDL), presence of circulating beta-very low density lipoproteins and elevated HDL cholesterol levels, in the presence of a very low, or undetectable, postheparin plasma hepatic lipase activity. Premature atherosclerosis and/or coronary heart disease may be associated. 